\title{
Knowledge and use of information and communication technology by health sci- ences students of the University of Ghana
}

\author{
Samuel Dery, Frances da-Costa Vroom, Anthony Godi, Seth Afagbedzi, and Duah Dwomoh
}

Ghana Med J 2016; 50(2): 180-188 DOI: http://dx.doi.org/10.4314/gmj.v50i3.10

\author{
Department of Biostatistics, School of Public Health, College of Health Sciences, University of Ghana, Legon, \\ Accra, Ghana \\ Corresponding author: Mrs Frances da-Costa Vroom \\ E-mail: fbvroom@ug.edu.gh
}

Conflict of interest: None declared

\section{SUMMARY}

Background: Studies have shown that ICT adoption contributes to productivity and economic growth. It is therefore important that health workers have knowledge in ICT to ensure adoption and uptake of ICT tools to enable efficient health delivery.

Objective: To determine the knowledge and use of ICT among students of the College of Health Sciences at the University of Ghana.

Methods: This was a cross-sectional study conducted among students in all the five Schools of the College of Health Sciences at the University of Ghana. A total of 773 students were sampled from the Schools. Sampling proportionate to size was then used to determine the sample sizes required for each school, academic programme and level of programme. Simple random sampling was subsequently used to select students from each stratum. .

Results: Computer knowledge was high among students at almost $99 \%$. About $83 \%$ owned computers $(\mathrm{p}<0.001)$ and self-rated computer knowledge was also $87 \%(\mathrm{p}<0.001)$. Usage was mostly for studying at $93 \%(\mathrm{p}<0.001)$.

Conclusions: This study shows students have adequate knowledge and use of computers. It brings about an opportunity to introduce ICT in healthcare delivery to them. This will ensure their adequate preparedness to embrace new ways of delivering care to improve service delivery.

Funding: Africa Build Project, Grant Number: FP7-266474

Keywords: ICT, health professionals, knowledge, students

\section{INTRODUCTION}

The use of information and communication technology (ICT) for healthcare delivery in the developed countries has been widely explored with most developed countries making great advances. ${ }^{1}$ Developing countries on the other hand are seeing a proliferation of eHealth pilots but few full scale implementations. ${ }^{2}$ Some reasons given for the case of "pilotitis" in the eHealth arena in developing countries are lack of infrastructure, donor funded projects and inadequate skilled personnel to manage these eHealth projects. ${ }^{3,4}$ The problem of inadequate ICT skills on the part of health professionals goes a long way to affect ICT deployments in the health sector.

ICT provides opportunities for individuals, medical professionals and healthcare providers to obtain information, communicate with other healthcare professionals and patients, offer primary healthcare support and promote preventive healthcare programmes. ${ }^{5}$ The emerging and changing technological development has led to a rethinking in the way technology can be used in healthcare delivery. According to Kwankam (2008, Unpublished report), technology enabled systems allow healthcare providers to deliver better support at lower cost and also contribute to quality health services. ${ }^{6}$ These systems collectively drive eHealth and provide lifesaving data and information for clinical and non-clinical use. EHealth, which has been defined by the World Health Organization as the cost-effective and secure use of ICT in support of health and health-related fields, including healthcare services, health surveillance, health literacy and health education, knowledge and research ${ }^{7}$ holds the key to improving healthcare delivery. 


\section{Original Article}

To harness the benefits of eHealth in Ghana's health sector, the Ministry of Health $(\mathrm{MoH})$ and the Ghana Health Service (GHS) developed an eHealth strategy ${ }^{8}$ with the goal of harnessing the potentials of ICT to improve the health status of people living in Ghana. In meeting this goal the strategy is seeking to provide options to support decision-making by health care providers, health service managers and consumers of health services thereby making the health sector more responsive to the needs of individuals, families and communities.

However, the strategy recognizes in no uncertain terms that the MoH does not have adequate staff with skills in eHealth systems and that some of the biggest challenges to eHealth capacity building in Ghana is the shortage of qualified, trained health care professionals and training resources. ${ }^{8}$ It has been proposed as part of the solutions to the eHealth capacity challenges, to engage all health training institutions to include basic practical ICT skills that will enable graduates to be conversant with tools, equipment and systems that support eHealth at their level.

Literature on the knowledge, attitudes and practices of students towards eHealth, computer and Internet use are minimal in Ghana. Two studies conducted by Achampong and Pereko in 2010, showed a 77\% level of confidence in using computers among medical students in one Ghanaian Medical School. ${ }^{9}$ Addah $^{10}$ also assessed ICT proficiency and use among students at a medical school in Ghana and found 56\% proficiency rate among the students. Both studies were conducted among medical students and therefore did not include students of other health professions. While these two studies show moderate proficiency, it is important efforts are made to improving the ICT capacity of healthcare professional during their training. Training the health workforce with and in ICT should be a requirement in the health training institutions. This paper therefore sought to explore the knowledge and use of ICT tools by students of the College of Health Sciences, University of Ghana

\section{METHODS}

This paper is part of a cross-sectional study conducted to investigate the knowledge, attitudes and use of ICT tools (computers, mobile phones/devices and Internet) and eHealth in general by students of the College of Health Sciences, University of Ghana. The study was conducted in the year 2014 in the College of Health Sciences, University of Ghana. The College is made up of five schools namely; Public Health, Medicine and Dentistry*, Pharmacy, Nursing and Allied Health.

Students were sampled from first year to the final years of the various academic programmes. The total number of students from the College of Health Sciences at the time of study was 2,734 . Based on a confidence level of $95 \%$, precision of $3 \%$, unknown proportion of students who are well-informed in relation to knowledge on ICT was assumed to be $50 \%$ and response rate of $90 \%$, the minimum sample size obtained for the study was 815 . Sampling proportionate to size was then used to determine the various sample sizes required for each school, academic programme and level of programme. Simple random sampling was then used to select students from each level of academic progression from an existing sampling frame (list of students from the various schools).

Questionnaires were self-administered by students (from level 100-700) offering various programmes in the College. The questionnaire was made up of seven sub-sections which included Background Information, General Computer Knowledge and Usage, Attitude and Perception towards/in favour/against Internet use, Attitude and perception towards E-Learning, Electronic Health Records and Mobile Learning.

Chi-square tests were used to investigate if the distributions of categorical responses varied significantly across the various schools. Multiple response Chi-square tests were used in instances where the variable allowed for such responses. Fisher's exact test was used where categorical response frequencies were low (i.e. expected cell frequency $<5$ ).

Medians and inter-quartile ranges were reported for central tendency where the variables of interest were grossly non-normal. Kruskal-Wallis rank test was used to test for differences in values across the schools, otherwise, means and standard deviations were reported where the variable of interest was approximately normal with one-way analysis of variance (ANOVA) used to test for such differences.

Missing values were accounted for with regards to percentage distributions in the tables but not shown except in instances where such missing values exceeded $10 \%$ of overall responses and were converted into additional categories labelled 'No response' and shown. Missing values not shown in the tables were excluded from tests but in instances where they were large enough to be classified as 'No response' and shown in the tables, they were included in the tests.

Ethical approval for this study was obtained from the Noguchi Memorial Institute for Medical Research (NMIMR) Institutional Review Board (IRB) (Certified protocol number 096/12-13). 


\section{RESULTS}

Socio-demographic characteristics of respondents A total of 773 respondents were surveyed with a response rate of $95 \%$. There were relatively equal numbers of male and female respondents with males making up $49.6 \%$ of total participants. Age range was between 18 and 53 years with a median age of 22 years. There were significant differences in age distribution across the schools with majority of respondents belonging to the $20-24$ age group. Health sector work experience was heavily skewed towards respondents from Public Health followed by the Pharmacy and Nursing schools. Average overall work experience was about 4 years and 2 months. Almost all respondents from all the schools were single with the exception once again of those from Public Health who were mostly married. Majority of the respondents were still at the undergraduate level except for Public Health which had quite a large proportion of postgraduates. There was no distinct trend in distribution of respondents across the various levels and schools. Majority of respondents were at the lower levels of under graduate study (Level $100-400$ ). There were no tests on differences in type and level of study across the schools due to the inapplicability of some types and levels in some schools. Socio-demographic characteristics can be found in Table 1 .

\section{Exposure and use of computers}

Almost all respondents had ready access to a computer with no differences in such access. There were however significant differences in ownership with Public Health having the highest level and Allied Health the least, although overall ownership was quite high in all schools. With the exception of Public Health, most respondents had their first computer use experience from primary and secondary school as well as the home. There were significant differences in this though with overall mean number of years since first use at 8 years.

Majority of respondents used the computer 5- 7 days per week with quite a large proportion not being able to clearly determine their frequency of use, perhaps because it was irregular for such people. There were significant differences in frequencies of what they use the computers for with majority using it for learning across all schools. There were quite a high number of respondents who used computers for sending and receiving emails, social networking and entertainment. Pharmacy led in the use of computers for studying, social networking and entertainment while Public Health led in the use of computers for emails and business. Respondents from Public Health used it the most for business (Table 2).

\section{Experience with computers and the Internet}

A very high proportion of respondents have ever used the Internet with almost $100 \%$ usage across all schools. There was however a significant difference with regards to the mean length of Internet experience with the difference between the Medical School (having the longest) and Allied Health (the lowest) being about 2 to 3 years. Overall, the mean usage experience was about 7 years. Internet usage frequency also varied significantly across the schools. Majority of respondents used the Internet at least 3 days per week with Pharmacy respondents having the highest proportion who used it 5 7 days per week. The Dental School had the highest proportion of respondents who used it $3-4$ days per week.

On computer training ever received, almost all the respondents had undertaken some form of training with most indicating self-guided learning as their mode of learning about computers. Few respondents reported having undertaken a computer science or IT related course. Pharmacy had the highest proportion of respondents who have ever undertaken such self-guided learning about computers with the lowest being the Dental School. The Pharmacy and Medical schools had the highest proportions that have ever undertaken some computer science or IT related courses. There were significant differences in computer training ever received across the schools though (Table 3).

Most of the respondents rated themselves as "Good" $(43.1 \%)$ or "Very good" $(36 \%)$ with regards to selfassessment of computer skills. Overall, majority saw themselves as "Good", the highest proportion being within the Dental School, the lowest within Public Health. There was a considerable gap between Medical students who assessed themselves as "Excellent" and those from Nursing. Almost all the respondents were willing to learn more about computers though with fewer numbers willing to do so for work. Differences in this self-assessment and willingness to learn more about computers across the schools were significant as well.

\section{Email, Internet use and challenges}

Over $88 \%$ of all respondents had an email address with Pharmacy having the highest and Allied Health the lowest ownership within schools. Most respondents also checked their emails at least weekly with majority doing so daily in all schools except Nursing where majority did so weekly. Majority of respondents also used email for educational purposes. The second most important use of emails were for entertainment in Allied Health, Dental, Medical and Pharmacy schools, information gathering in Nursing and Public Health schools. 


\section{Original Article}

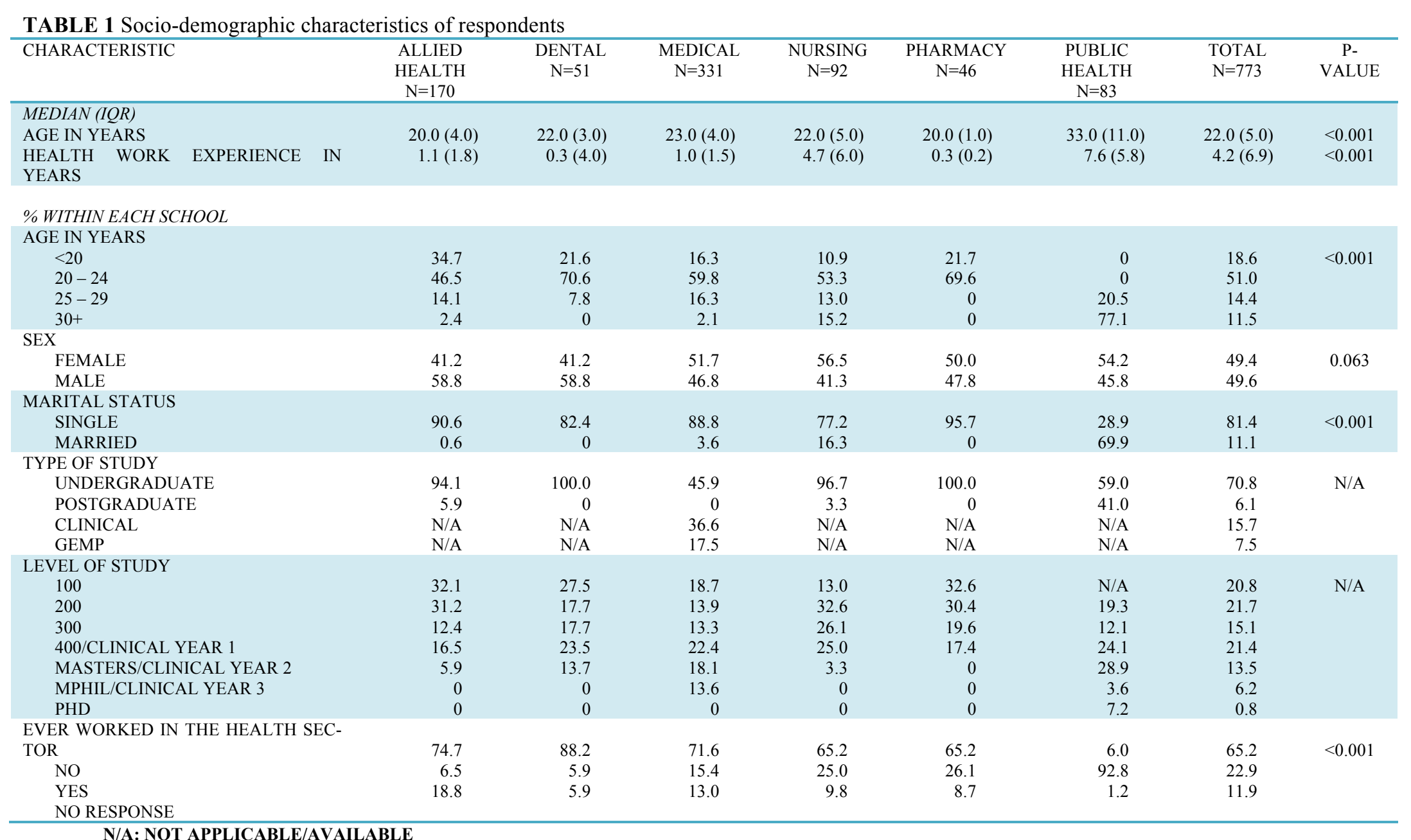




\section{Original Article}

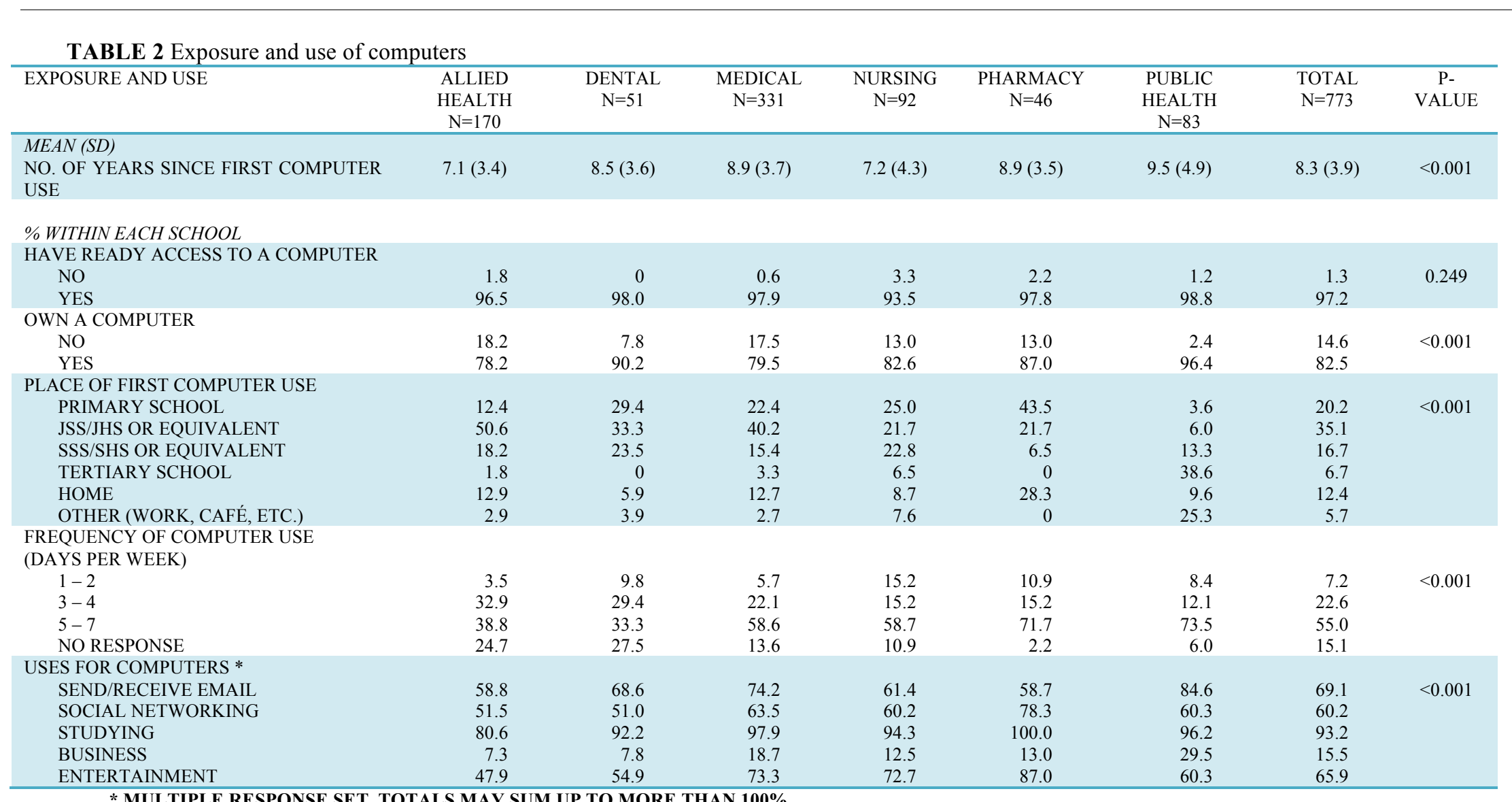




\section{Original Article}

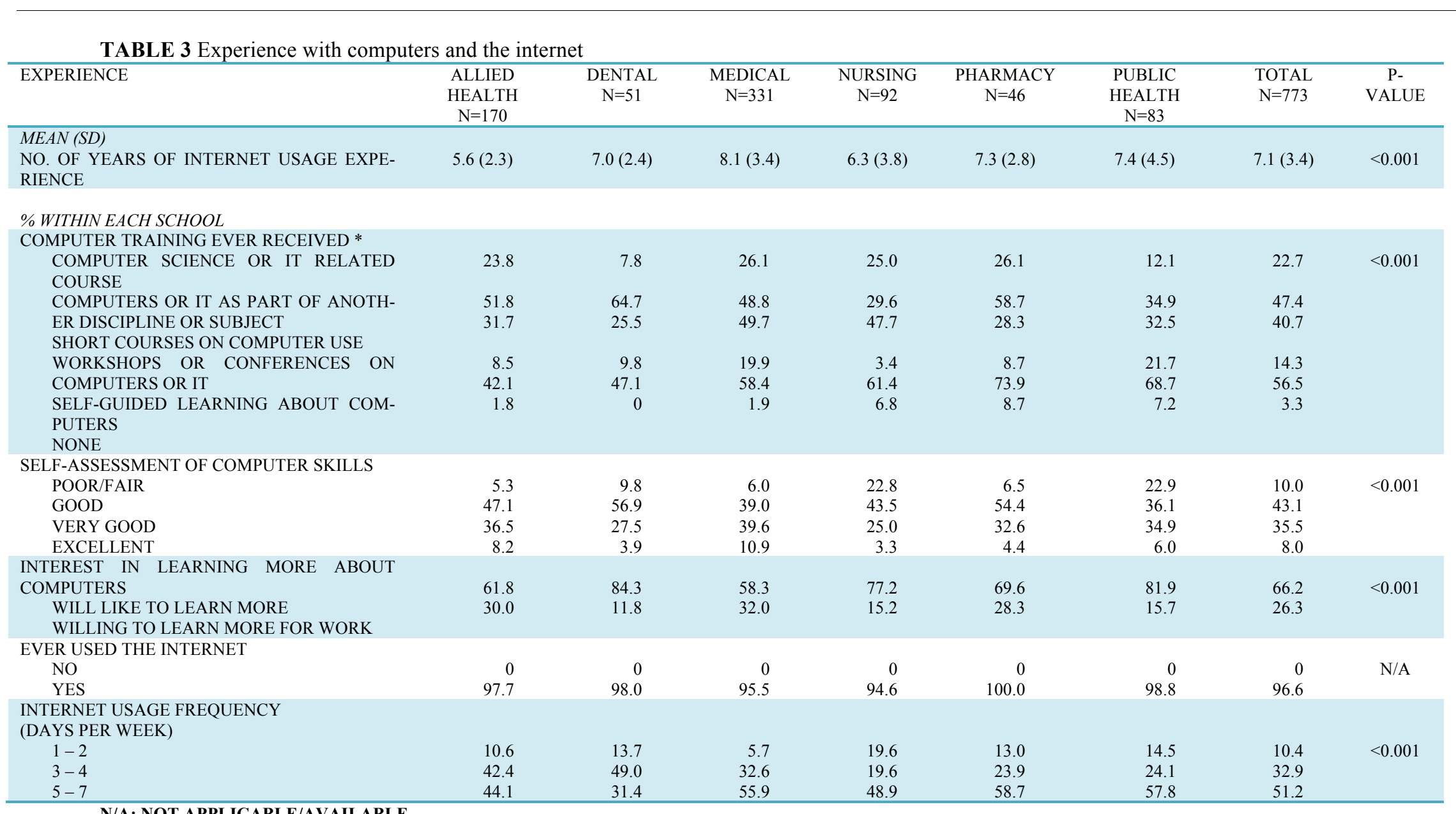

N/A: NOT APPLICABLE/AVAILABLE

* MULTIPLE RESPONSE SET, TOTALS MAY SUM UP TO MORE THAN 100\%. 


\section{Original Article}

\begin{tabular}{|c|c|c|c|c|c|c|c|}
\hline USAGE AND CHALLENGES & $\begin{array}{c}\text { ALLIED } \\
\text { HEALTH } \\
\mathrm{N}=170\end{array}$ & $\begin{array}{c}\text { DENTAL } \\
\mathrm{N}=51\end{array}$ & $\begin{array}{l}\text { MEDICAL } \\
\mathrm{N}=331\end{array}$ & $\begin{array}{c}\text { NURSING } \\
\mathrm{N}=92\end{array}$ & $\begin{array}{c}\text { PHARMACY } \\
\mathrm{N}=46\end{array}$ & $\begin{array}{c}\text { PUBLIC } \\
\text { HEALTH } \\
\mathrm{N}=83\end{array}$ & $\begin{array}{l}\text { TOTAL } \\
\mathrm{N}=773\end{array}$ \\
\hline \multicolumn{8}{|l|}{$\%$ WITHIN EACH SCHOOL } \\
\hline \multicolumn{8}{|l|}{ HAVE EMAIL ADDRESS } \\
\hline NO & 0 & 0 & 0 & 1.1 & 2.2 & 1.2 & 0.4 \\
\hline YES & 81.2 & 92.2 & 88.5 & 92.4 & 97.8 & 95.2 & 88.9 \\
\hline NO RESPONSE & 18.8 & 7.8 & 11.5 & 6.5 & 0 & 3.6 & 10.7 \\
\hline \multicolumn{8}{|l|}{ FREQUENCY IN CHECKING EMAIL } \\
\hline NEVER & 0.6 & 0 & 0.6 & 3.3 & 8.7 & 1.2 & 1.4 \\
\hline LESS THAN MONTHLY & 4.1 & 7.8 & 9.1 & 15.2 & 17.4 & 7.2 & 8.9 \\
\hline MONTHLY & 7.1 & 11.8 & 10.9 & 17.4 & 17.4 & 1.2 & 10.2 \\
\hline WEEKLY & 39.4 & 31.4 & 28.7 & 35.9 & 21.7 & 15.7 & 30.3 \\
\hline DAILY & 47.1 & 47.1 & 46.5 & 21.7 & 30.4 & 73.5 & 45.7 \\
\hline \multicolumn{8}{|l|}{ USUAL USES FOR THE INTERNET * } \\
\hline EDUCATION & 79.6 & 100.0 & 92.9 & 98.9 & 100.0 & 98.8 & 92.2 \\
\hline SHOPPING/GATHERING PRODUCT INFORMATION & 15.0 & 26.0 & 44.7 & 28.7 & 34.8 & 25.0 & 32.3 \\
\hline ENTERTAINMENT & 50.9 & 56.0 & 78.9 & 79.3 & 82.6 & 55.0 & 68.9 \\
\hline WORK/BUSINESS & 15.0 & 18.0 & 29.2 & 20.7 & 23.9 & 48.8 & 26.1 \\
\hline COMMUNICATION (EXCLUDING EMAIL) & 46.1 & 50.0 & 76.4 & 73.6 & 80.4 & 71.3 & 67.3 \\
\hline GATHERING INFORMATION FOR PERSONAL & 39.5 & 48.0 & 60.3 & 81.6 & 78.3 & 75.0 & 60.0 \\
\hline NEEDS & 13.8 & 30.0 & 36.0 & 33.3 & 34.8 & 23.8 & 29.0 \\
\hline \multicolumn{8}{|l|}{ WHILING AWAY TIME } \\
\hline \multicolumn{8}{|l|}{ CHALLENGES IN USING THE INTERNET * } \\
\hline INABILITY FINDING INFORMATION & 35.0 & 49.0 & 54.2 & 62.1 & 52.2 & 51.3 & 50.1 \\
\hline INABILITY TO EFFICIENTLY ORGANIZE GATH- & 30.6 & 38.8 & 23.4 & 29.9 & 23.9 & 20.5 & 26.5 \\
\hline ERED INFO. & 24.4 & 38.8 & 28.3 & 32.2 & 41.3 & 16.7 & 28.2 \\
\hline DIFFICULTY FINDING KNOWN WEBPAGES & 17.5 & 28.6 & 16.6 & 20.7 & 13.0 & 7.7 & 16.9 \\
\hline INABILITY TO RETURN TO VISITED PAGES & 14.4 & 16.3 & 18.8 & 2.3 & 4.4 & 2.6 & 13.1 \\
\hline DIFFICULTY DETERMINING WEB LOCATION & 30.6 & 44.9 & 39.9 & 56.3 & 54.4 & 32.1 & 40.3 \\
\hline SLOW WEBPAGE LOADING & 36.3 & 51.0 & 48.7 & 49.4 & 56.5 & 46.2 & 46.4 \\
\hline PROBLEMS WITH WEB BROWSER & 25.6 & 34.7 & 27.9 & 20.7 & 19.6 & 12.8 & 24.9 \\
\hline BROWSER INCOMPATIBILITY WITH SITES & 42.5 & 59.2 & 46.8 & 55.2 & 58.7 & 41.0 & 47.8 \\
\hline TOO MANY "JUNK" SITES & 36.3 & 53.1 & 56.2 & 70.1 & 71.7 & 53.9 & 54.0 \\
\hline SITES REQUIRING REGISTRATION & 19.4 & 28.6 & 19.2 & 28.7 & 17.4 & 24.4 & 21.4 \\
\hline \multirow[t]{2}{*}{ SITES WITH TOO MANY/USELESS GRAPHICS } & 17.5 & 26.5 & 24.4 & 28.7 & 15.2 & 21.8 & 22.7 \\
\hline & 30.0 & 44.9 & 42.5 & 72.4 & 65.2 & 57.7 & 46.6 \\
\hline $\begin{array}{l}\text { SLOW LOADING ADVERTISING BANNERS } \\
\text { SITES THAT REQUIRE MONEY FOR ACCESS }\end{array}$ & & & & & & & \\
\hline
\end{tabular}


The greatest challenge in using the Internet in the Medical, Nursing, Pharmacy and Public Health Schools was the requirement for registration by some websites. The respondents did not have much difficulty determining web locations. Allied Health and Dental School had challenges with too many "junk" sites (Table 4).

\section{DISCUSSION}

This study sought to explore the knowledge and use of ICT tools by respondents of the College of Health Sciences, University of Ghana. The study revealed that almost all the respondents (99\%) know how to use computers and $95 \%$ know how to use the Internet. The extent of computer usage varies from student to student with most using a computer on a daily basis (65\%). Knowledge of computer use is higher compared to some studies done in Ethiopia $(51 \%)^{11}$ and Ghana $(56 \%) .{ }^{10}$ Having access to a computer (desktop or laptop) is a necessary step to using computers. In all $97.2 \%$ of the respondents have access to a computer and $82.5 \%$ owned a computer. This is far higher than the proportion of Ghanaians who owned desktop computers and laptops $(18 \%$ and $19 \%$ respectively) or have access to computers (37-50\%). ${ }^{12}$ Again, this result is higher compared to a similar study that was done among students of the health sciences at the University of Gondar, in Ethiopia where $52.7 \%$ have access to computers. ${ }^{11}$ This result is also consistent with the study by Achampong and Pereko, that found $91.4 \%$ ownership of computers among medical student respondents of the University of Cape Coast in Ghana. ${ }^{9}$

The highest ownership of computers was found in the School of Public Health (96\%) compared with School of Allied Health (78\%). This could be due to the fact that most of the respondents of the School of Public Health $(93 \%)$ are/were employed and therefore can afford laptops as compared to the other schools (6-26\%).

A significant proportion of the respondents have had one form of formal training in the use of computers, however, most of them have also learned to use computers through self-guided approach. The desire to acquire skills could drive the individual to take the initiative of self-guided learning. However, considering the information overload when using the Internet, care must be taken to expose these respondents to the right sources of information and tools for self-guided learning. In addition, most respondents expressed the desire and willingness to learn more about computers and their application in their various areas of study.

It is also good to note that overall, $90 \%$ of the respondents rated their skills in computers as above average. Respondents at the School of Public Health rated their computer skills lower than respondents from the other schools. This positively correlates with the age group of most respondents at Public Health. Older health professionals are usually known to be less computer savvy and less interested in using computers for various activities. ${ }^{5}$ With the advances in information and communication technology, its use is increasing among respondents. Computer and Internet use have become part of the student's daily life. The results show that most respondents are actually using the computer as a tool to facilitate their academic work (93\%), email communication $(70 \%)$, social networking $(60 \%)$ and entertainment $(66 \%)$. This is an improvement as compared to the work of Addah $^{10}$ in 2012 where $37.8 \%$ were using ICT resources for their academic work, and $85.2 \%$ for social purposes.

The study has revealed that knowledge and use of computers among the College of Health Sciences students is high and the confidence to use ICT tools is also high. However, most of the computer software used by the respondents are basic utility software that are not directly related to eHealth applications. The College and the Ghana Health Service can therefore take advantage of the willingness of respondents to learn more about eHealth applications and introduce eHealth related courses for each of the schools.

\section{CONCLUSION}

Overall, computer knowledge, use and ownership were high among respondents in the College of Health Sciences. This serves as good grounds for the introduction of eHealth into Ghana's healthcare delivery. It provides an opportunity for eHealth to be introduced fully to improve healthcare delivery.

\section{REFERENCES}

1. Howitt P, Darzi A, Yang G-Z, Ashrafian H, Atun R, Barlow J, et al. Technologies for global health. Lancet. 2012;380(9840):507-35.

2. Lewis T, Synowiec C, Lagomarsino G, Schweitzer J. EHealth in low- and middle-income countries: findings from the Center for Health Market Innovations. Bull World Health Organ. 2012;90(5):332-40.

3. Yusif S, Soar J. Preparedness for eHealth in developing countries: the case of Ghana. J Health Inform Dev Ctries. 2014;8(2).

4. Piette JD, Lun KC, Moura LA, Jr., Fraser HS, Mechael PN, Powell J, et al. Impacts of eHealth on the outcomes of care in low- and middle-income countries: where do we go from here? Bull World Health Organ. 2012;90(5):365-72.

5. Gour N, Srivastava D. Knowledge of computer among healthcare professionals of India: a key to- 
ward eHealth. Telemed J E Health. 2010;16(9):95762.

6. World Health Organisation. RESOLUTIONS AND DECISIONS 2005. Available from: http://apps.who.int/gb/ebwha/pdf_files/WHA58/WH A58 28-en.pdf.

7. Ministry of Health. National EHealth Strategy. In: Ministry of Health Ghana, editor.

8. Achampong EK, Pereko KKA. Computer Skills and the Training of Medical Respondents in a Ghanaian Medical School. EJHI. 2010;5(2):e12.

9. Addah J. Proficiency in Information Communication Technology and its Use: A Survey among Clinical
Respondents in a Ghanaian Medical School. Int $J$ Comput Appl 2012;45(24).

10. Woreta S, Kebede Y, Zegeye D. Knowledge and utilization of information communication technology (ICT) among health science respondents at the University of Gondar, North Western Ethiopia. $B M C$ Med Inform Decis Mak. 2013;13(1):1-7.

$\rightarrow$ Balancing Act. Face-To-Face Survey Overview Summary Results2014 15/03/2015. Available from: http://www.balancingactafrica.com/sites/balancingac tafrica.com/files/products/2.\%20F2F\%20Survey $\% 20$ Results\%20FV.pdf $\bullet$ 